Published in final edited form as:

JAMA. 2008 December 10; 300(22): 2631-2637. doi:10.1001/jama.2008.804.

\title{
A randomized controlled trial of financial incentives for weight loss
}

\author{
Kevin G. Volpp ${ }^{1,2,3,4}$, Leslie K John ${ }^{5}$, Andrea B Troxel ${ }^{6}$, Laurie Norton ${ }^{1}$, Jennifer \\ Fassbender $^{6}$, and George Loewenstein ${ }^{5}$ \\ ${ }^{1}$ Center for Health Equity Research \& Promotion, Philadelphia Veterans Affairs Medical Center \\ ${ }^{2}$ Department of Medicine, University of Pennsylvania School of Medicine \\ ${ }^{3}$ Department of Health Care Systems, the Wharton School, University of Pennsylvania \\ ${ }^{4}$ Leonard Davis Institute of Health Economics \\ ${ }^{5}$ Department of Social and Decision Sciences, Carnegie Mellon University \\ ${ }^{6}$ Center for Clinical Epidemiology and Biostatistics and Department of Biostatistics and \\ Epidemiology, University of Pennsylvania
}

\begin{abstract}
Context-Identifying effective strategies for treating obesity is both a clinical challenge and a public health priority due to the health consequences of obesity.
\end{abstract}

Objective-To determine whether common decision errors identified by behavioral economists such as prospect theory, loss aversion, and regret could be used to design an effective weight loss intervention

Design-3-arm randomized controlled trial in which participants were randomized to either usual care (weigh ins once a month) or one of two financial incentives arms. One incentive arm used deposit contracts in which participants put their own money at risk (matched 1:1 by the study) which they would lose if they failed to lose weight. The second used lottery-based incentives in which participants who met the weight loss target had each day a 1 in 5 chance of winning a small reward (\$10) and a 1 in 100 chance of winning a large reward (\$100). All participants were given a weight loss goal of 1 pound per week for 16 weeks, and results were analyzed using intention-totreat analysis of variance models.

Setting-Philadelphia Veterans Affairs Medical Center.

Corresponding author: Kevin G. Volpp, MD, PhD, Division of General Internal Medicine \& Department of Health Care Systems, University of Pennsylvania School of Medicine and the Wharton School, 1232 Blockley Hall, 423 Guardian Drive, Philadelphia PA 19104-6021, Phone: 215-573-0270, Fax: 215-573-8778, volpp70@ wharton.upenn.edu.

Authorship contributions:

Conception and design: Volpp, Loewenstein

Acquisition of data: Volpp, Norton, John, Fassbender

Analysis and interpretation of data: Volpp, Troxel, John, Loewenstein

Drafting of the manuscript: Volpp, John, Loewenstein

Critical revision of the manuscript for important intellectual content: Volpp, John, Troxel, Norton, Fassbender, Loewenstein Statistical Analysis: Troxel, John, Volpp, Loewenstein

Obtaining funding: Volpp, Loewenstein

Administrative, technical, or material support: Volpp, Norton, Fassbender, Loewenstein

Supervision: Volpp, Loewenstein

There are no known financial conflicts of interest among any of the authors including but not limited to employment/affiliation, all grants or funding, honoraria, paid consultancies, expert testimony, stock ownership or options, and patents filed, received or pending. 
Patients-57 patients with BMIs between 30-40 aged between 30 and 70, with no contraindications for study participation.

Main Outcome Measures-Weight loss after 16 weeks.

Results-Participants in both incentive groups lost significantly more weight than participants in the control group (3.9 pounds); (Lottery $=13.1 \mathrm{lbs}$; p-value for lottery vs. control .014; deposit contract $=14.0 \mathrm{lbs}$, p-value vs. control .003$) .47 .4 \%$ of deposit contract participants and $52.6 \%$ of lottery arm participants met the 16-pound weight loss goal compared to $10.5 \%$ in the control group (p-value 0.014.). By the end of 7 months, substantial amounts of weight were regained; however, incentive participants weighed significantly less than they did at the study start whereas controls did not. Low lost to follow-up rates (7.0\%) during the weight loss phase of the study suggest that both incentive systems were successful in keeping participants engaged in the study.

Conclusions-Incentive approaches based on behavioral economic concepts could have a major impact in reducing the incidence of obesity-related illnesses.

\section{Introduction}

From 1960 to 2004, the proportion of Americans who are obese climbed from approximately $13 \%$ to $31 \% .{ }^{1}$ In $2004,71 \%$ of U.S. adults were overweight or obese according to standard definitions, ${ }^{2}$ and at present obesity falls just behind smoking as a preventable cause of premature death. ${ }^{3}$ New strategies are needed to help reduce the rate of obesity in the US population.

Behavioral economics has identified several patterns of behavior that help to explain why people engage in self-destructive behavior, including the tendency to put disproportionate weight on immediate benefits, such as the pleasure of eating, relative to the much smaller weight put on delayed benefits, such as enjoying good health..$^{4}{ }^{5}$ However, these decision errors can be used to help people instead of hurt them and have particular applicability to health behaviors such as obesity. ${ }^{6}$

For this study, we designed two incentive-based approaches for losing weight that magnify the impact of incentives using insights from behavioral economics. The two interventions consisted of a lottery-based arm in which participants played a lottery and received the earnings if they were under the target weight and a deposit contract condition in which participants put their own money at risk, which they lost if they failed to achieve weight goals. The effect of these incentives in achieving weight loss over a 16 week period were tested vs. a control group in a 3-arm randomized controlled trial among obese and overweight study participants at the Philadelphia Veterans Affairs Medical Center (PVAMC).

\section{Materials and Methods}

\section{Study Population}

The flow of participants through enrollment, intervention, and follow-up is shown in Figure 1. PVAMC participants meeting initial eligibility requirements were recruited using mailings, with those who called in to express interest further screened for eligibility. Eligible participants were between age 30 and 70 (inclusive) and had a Body Mass Index (BMI) of 30-40 (inclusive). Exclusion criteria included current treatment for drug or alcohol use, consumption of $>5$ alcoholic drinks per day, myocardial infarction or stroke within the past 6 months, current addiction to prescription medicines or street drugs, illiteracy, serious psychiatric diagnoses, and participation in another weight loss program. 


\section{Randomization Procedures}

Participants were randomized evenly to the three experimental conditions using a block size of six, with stratification based on sex and age (30-49 vs. 50-70). Sealed envelopes generated by the statistician were used within each of the strata so that the research coordinator who enrolled the participants did not know the randomization assignment of the next participant until it had been assigned. Neither the participants nor the coordinator could be blinded to the randomization assignment given the nature of the intervention.

\section{Study Protocol}

The protocol was approved by the Institutional Review Board of the Philadelphia Veterans Affairs Medical Center and the University of Pennsylvania, and all participants provided informed consent. Fifty-seven participants were randomly assigned to participate in either a weight monitoring (WM) program involving monthly weigh-ins, or the same program with one of two financial incentive plans (deposit contract or lottery). At initial enrollment, participants had a 1 hour one-on-one consultation with a dietician covering diet and exercise strategies for weight loss. All participants were given a free scale with precision to 0.2 pounds.

Participants in incentive arms were given a chart at the initial visit depicting the daily weight goals they needed to attain to qualify for the incentives, with all participants having a goal weight loss of 16 pounds over 16 weeks (Figure 2). Recruitment of subjects began in June, 2007 and ended in October, 2007, with follow-up ending January, 2008.

Deposit contract financial incentive (DC) participants were given the opportunity to contribute between $\$ 0-\$ 3.00$ for each day of the month of their own funds, refundable at the end of the month only if they met or exceeded their weight loss goal. As an incentive for participants to contribute to deposit contracts, we matched their money 1:1 and added a fixed payment of $\$ 3$ per day. Thus, participants in this condition had the opportunity to earn $\$ 168$ net (\$252 gross) per month. Participants decided at the beginning of each month how much they wished to deposit for the upcoming month.

Participants in the lottery incentive arm (L) were eligible for a daily lottery prize with an expected value of $\$ 3 /$ day, but only if, prior to the lottery being resolved, they had reported a weight at or below their weight loss goal. The lottery provided infrequent large payoffs (a 1 in 100 chance at a $\$ 100$ reward) and frequent small payoffs (a 1 in 5 chance at a $\$ 10$ reward). Each lottery incentive participant chose a 2-digit number upon recruitment, e.g., "27." A two digit number was randomly generated every day. If the first digit generated was a "2" or the last digit was a"7" (which has approximately a 1 in 5 chance), and the participant met his/her daily weight loss goal, he/she would win $\$ 10$. If the randomly drawn number was " 27 " (a 1 in 100 chance), the person would win $\$ 100$.

Both deposit contract and lottery incentive participants were instructed to: a) weigh themselves each morning before eating or drinking and after urinating, b) record their weights, and c) call in their weight to the project staff by 12 noon. Every day, they were sent a message via text pager indicating whether they were on track toward attaining their monthly weight loss goal and how much they had won that day in incentives. Participants who sent their early morning weights received rapid, same-day feedback about their progress and earnings, if any. Non-adherent participants received feedback about what their earnings would have been had they met their target weight.

Participants returned to the clinic at the end of each month to be weighed and the incentive group participats received weight loss incentives if their weight on the clinic scale was below the target for that month. DC participants were asked how much they wanted to 
deposit for the subsequent month. To minimize loss to follow-up rates at monthly weigh-ins, all participants received $\$ 20$ each time they attended a monthly weigh-in regardless of weight loss.

Deposit contract money that was forfeited by participants failing to lose a sufficient amount of weight was contributed to a pool of money that was divided equally among deposit contract participants who lost 20 pounds or more over the 16 weeks. All participants in the lottery and deposit contracts who lost more than 20 pounds by the end of the four months were eligible for this additional bonus, which we guaranteed at the beginning of the study would be at least $\$ 50$.

A key feature of the weight loss trajectory is that it was reset at monthly intervals for those failing to attain goals. This feature was important for reducing the likelihood of dropout among participants who failed to lose sufficient weight during a particular month.

Participants above their weight loss goal at the end of a month were given a "fresh start" in which the overall weight loss goal stayed the same but the slope of the trajectory was adjusted (i.e., steepened) such that the participant need not "binge diet" to resume receiving incentive payments (see "Fresh start trajectory" in Figure 2, which assumes the participant lost $2 \mathrm{lbs}$. instead of $4 \mathrm{lbs}$. in first month). Keeping the overall weight loss goal constant made the procedure fair for those participants who maintained the ideal trajectory, while allowing participants who lapsed to get back on track more easily.

Study participants who lost at least $5 \mathrm{~kg}$ were randomized to receive either incentives for maintenance of weight loss vs. monthly weigh ins in an exploratory analysis. However, only 24 participants qualified for this intervention (4/19 in control group, 10/19 in deposit contract arm, 10/19 in lottery arm), and fewer still (18) agreed to participate (3/19 in control group, 8/19 in deposit contract arm, 7/19 in lottery arm). Those who did not participate in the maintenance phase were all scheduled to return to the office for a 7 month follow-up weigh-in. These weigh-ins were conducted at a median of 7 months and a mean of 8 months from the start of the study.

\section{Statistical Analyses}

Our primary outcome was weight loss after 16 weeks. We hypothesized that subjects in each of the incentive arms would achieve significantly greater weight loss than control group subjects. Primary analyses were unadjusted intent-to-treat analyses testing for differences between each of the incentive and control groups in weight loss after 16 weeks using twosided t-tests. All participants lost to follow-up were treated as having their weight return to baseline. Unadjusted odds ratios for the likelihood of reaching the 16-pound weight loss goal were estimated and compared with odds ratios adjusted for the stratification variables (gender and age) as well as other baseline covariates. The similarity of the treatment and control groups with respect to covariates at baseline was analyzed by Pearson's $\chi^{2}$ test for categorical variables and Student's $t$ test or Wilcoxon rank sum for continuous variables, as appropriate.

Our secondary outcome was weight loss after 7 months, which was the median follow-up interval among non-participants in the maintenance phase. Relative to control participants, a greater proportion of the incentive participants was enrolled in the maintenance phase; however, the degree of weight regain was statistically similar in both the study participants who enrolled in the maintenance weight loss intervention and those who simply came in for follow-up weigh-ins. In our secondary, exploratory analyses, we therefore assessed average 7-month follow-up weight loss across the three conditions to which participants had been randomly assigned at the start of the study (i.e. WM, DC, L), using two-sided t-tests to compare each incentive group to the control group, as for the primary outcome above 
Because of the variation in timing of the planned follow-up visit we repeated this analysis using the mean follow-up time ( 8 months) rather than the median. All participants lost to follow-up were treated as having their weight return to baseline.

Our power calculations were based on finding a difference in weight loss of 11 pounds ( 5 kilograms) at 16 weeks, which we viewed as a threshold for a clinically significant degree of weight loss in this population. ${ }^{7}, 8$ Making the assumption of an 11 pound standard deviation for weight loss and using a two-sided alpha of 0.025 , we required 19 participants per arm to provide $80 \%$ power to find an 11 pound difference in weight loss between the groups.

\section{Results}

No significant differences were found in the baseline characteristics of any of the groups (Table 1). The sample was predominantly male, with total household incomes of about $\$ 30,000$, and a mean enrollment BMI of between 33.8-35.5 across the 3 groups. Participants in all 3 groups rated the importance of controlling their weight to be high on a 10-point scale (9.1-9.3) and had high confidence in their ability to lose weight (8.3-8.5).

$89.5 \%$ (or 17/19) of deposit contract participants deposited money into deposit contracts initially. 14/17 participants who made initial deposits either held constant or increased their contributions each month. The average daily deposit contract contribution was $\$ 1.56$; the median was $\$ 1.49$.

Mean weight loss at 16 weeks was greater in each of the incentive groups $(\mathrm{L}=13.1 \mathrm{lbs}$; DC $=14.0 \mathrm{lbs})$ relative to the control group $(\mathrm{WM}=3.9 \mathrm{lbs})(\mathrm{L}: \mathrm{t}(1)=2.57, \mathrm{p}=.014$; DC: $\mathrm{t}(1)=$ $3.2, \mathrm{p}=.003$ ) (Table 2 ). Whereas only $10.5 \%$ of control participants attained the 16 pound weight loss goal, most incentive participants $\operatorname{did}(\mathrm{L}=52.6 \%, \mathrm{DC}=47.4 \%)$ - a statistically significant difference $\left(\chi^{2}(2)=8.59, \mathrm{p}=.014\right)$. The odds of achieving the 16 pound weight loss goal were significantly greater in both the deposit (OR 7.7, 95\% CI [1.4, 42.7]) and lottery incentive (OR 9.4, 95\% CI 1.7, 52.7]) arms relative to the control group (results not shown in Table). Results were qualitatively similar after adjusting for the stratification variables of age and gender. Exploratory subgroup analyses revealed qualitatively similar patterns regardless of age, income or initial BMI. The only other significant predictor of weight loss was race, which did not affect the relative effectiveness of the incentive conditions.

The percentage of participants losing at least 20 pounds was $36.8 \%$ in the deposit contract group, $26.3 \%$ in the lottery arm, and $5.3 \%$ in the control $\left(\chi^{2}(2)=5.58, p=.061\right)$. These participants each received a $\$ 50$ bonus; in addition, deposit contract participants each received $\$ 46$ (their share of the total amount forfeited by participants in the DC arm who did not lose weight). All but one of the participants in the two incentive arms who were not lost to follow-up (33 out of 38) lost weight over 16 weeks.

Over the course of the 16-week study, the average amount of money earned in weight loss incentives was $\$ 378.49$ in the deposit contract condition, and $\$ 272.80$ in the lottery condition. The lost to follow-up rate of 7.0\% (4/57 participants) was low in comparison with typical rates in weight loss studies. ${ }^{9}$ Of those who completed the study, the daily call-in rate was extremely high and not statistically different between incentive conditions ( $\mathrm{DC}=$ $94.0 \%, \mathrm{~L}=97.4 \% \mathrm{~F}=2.43, \mathrm{p}=.130$ ). There were no significant adverse events related to the study in either of the intervention groups.

Study participants in both the lottery and deposit contract arms gained weight between the end of the weight loss incentive intervention and the end of 7 months (Figure 3). While the net weight loss between enrollment in the study and the end of 7 months was larger in the 
incentive arms $(\mathrm{L}=9.2 \mathrm{lbs}$; $\mathrm{DC}=6.2 \mathrm{lbs})$ than in the control group $(\mathrm{WM}=4.4 \mathrm{lbs})$, these differences were not statistically significant $(\mathrm{L}: \mathrm{t}(1)=1.21, \mathrm{p}=.23$; DC: $\mathrm{t}(1)=.0 .52, \mathrm{p}=$. $61)$. At the end of 7 months, however, lottery and deposit contract participants weighed significantly less than they did at the beginning of the study $(\mathrm{L}$ : $(\mathrm{t}(18)=-2.87, \mathrm{p}=.010$; $\mathrm{D}$ : $\mathrm{t}(18)=-2.41, \mathrm{p}=.027$ ), whereas control participants did not (WM: $\mathrm{t}(18)=-1.97, \mathrm{p}=.064)$. At 8 months, weight loss among deposit contract participants is less than at baseline to only a marginally significant degree (p-value 0.10 ); otherwise, follow-ups results of maintenance subjects at the end of 8 months were qualitatively similar.

\section{Discussion}

This study demonstrates the effectiveness of incentive systems based on behavioral economics in promoting weight loss. Lost to follow-up rates were much lower than is typical in weight loss studies, suggesting that this approach was successful in keeping participants engaged, and significant weight loss was achieved without coupling the incentive program with an intensive, expensive weight loss program. Weight loss of the magnitudes obtained in the incentive conditions has been shown to improve immediate outcomes such as blood pressure, glycemic control, and serum lipid levels, and a mean weight loss of $5.5 \mathrm{~kg}$ has been associated with a reduction in the incidence of diabetes of 58\% over an average followup interval of 2.8 years. ${ }^{7,8}$ However, substantial amounts of weight were regained between the end of the weight loss phase and the follow-up 3 months later. This suggests that to achieve long-term weight loss such programs need to run for a longer period of time, and the optimal duration of such programs is an important question for further investigation.

Our work expands understanding of how financial incentives can contribute to weight loss. In a recent study, Finkelstein and colleagues found that over a 3 month period participants offered $\$ 14$ per percentage point of weight loss lost 4.7 pounds and participants offered $\$ 7$ per percentage point of weight loss lost 3.0 pounds compared to 2.0 pounds among control group participants. ${ }^{10}$ Jeffrey and colleagues had earlier demonstrated that significant weight loss could be achieved using deposit contracts, ${ }^{11,12}$ but these studies had required substantial up front payments and the incentive programs were tied to intensive weight loss programs. The large up front payments (equivalent to about $\$ 800$ in today's dollars) led to about $15 \%$ of potential participants responding to invitations to join the Jeffrey study in contrast with $81.4 \%$ in this study. Incentive-based approaches that involve applying incentives to participants rather than providers have great potential to change participant health behaviors. ${ }^{6,13-16}$ This is important because unhealthy behaviors such as smoking, poor diet, and sedentary lifestyles may account for as much as $40 \%$ of premature mortality in the United States, whereas deficiencies in health care delivery may account for only $10 \%$ of premature mortality. ${ }^{17}$

The interventions in this study were designed to take advantage of several effects identified in the behavioral economics literature. First, consistent with research showing that even small rewards and punishments can have great incentive value if they occur immediately, ${ }^{18-21}$ participants received rapid feedback about whether they won and nonadherent participants received feedback about whether they would have won had they been adherent. Second, based on research showing that people are motivated by the experience of past rewards and the prospect of future rewards, ${ }^{22}$ and that people are particularly emotionally attracted to small probabilities of large rewards, ${ }^{23}$ the lottery provided frequent small payoffs (a 1 in 5 chance at a $\$ 10$ reward) and infrequent large payoffs (a 1 in 100 chance at a $\$ 100$ reward). Third, research on decision making has found that the desire to avoid regret is a potent force in decision making under risk, ${ }^{24}$ so by giving participants who did not lose weight feedback about what they would have won had they been adherent, the incentive scheme maximized the anticipated threat of regret by people who fail to adhere. 
Anticipated regret has been shown to affect a variety of preventive behaviors, such as the significant increase in vaccination use among people who experienced illness after failing to get vaccinated. ${ }^{25}$ Lotteries also provide variable reinforcement, an approach known to be especially effective in reinforcing behavior. ${ }^{26}$ The use of deposit contracts is a powerful mechanism for inducing behavior change that is based on "loss aversion," a psychological concept first described by Nobel Prize winner Daniel Kahneman and Amos Tversky in 1979. Loss aversion has been used to explain many inconsistencies in traditional economic choice models, including anomalous patterns of choice under conditions of uncertainty. ${ }^{27,28}$ Critical to using loss aversion to motivate behavior is the concept of decision isolation; people react so powerfully to small losses and gains in part because they consider them in isolation and fail to integrate them psychologically with the often much larger fluctuations in income arising from work-earnings and investments. ${ }^{29,30}$

An important outstanding question is the sustainability of weight loss achieved through incentives, as maintenance of successful weight loss has been a big challenge. ${ }^{31,32}$ Our results clearly indicate that incentive programs must be focused on both attainment of initial weight loss and maintenance of weight loss. The need for effective weight management strategies has taken on increasing urgency because of markedly increasing rates of obesity. ${ }^{2,33,34}$ Many behavioral interventions and pharmacotherapy are costly and generally produce only modest ( 3 to $5 \mathrm{~kg}$ ) weight loss. ${ }^{35}$ Surgical treatment, while effective in inducing weight loss in morbidly obese participants, has a relatively high rate of complications and high costs. ${ }^{36}$

While the study was limited to veterans at a single facility, we have no reason to think that the participants were different than those at other facilities in terms of likely responsiveness to the intervention, though follow-up studies should examine the relative responsiveness to incentives of men and women in different health care settings.

In conclusion, incentive approaches based on behavioral economic concepts appear to be highly effective in inducing initial weight loss. These approaches could be highly effective in modifying a wide range of difficult to change health behaviors. Further work is needed to test the effectiveness and cost effectiveness of these approaches in achieving sustained weight loss.

\section{Acknowledgments}

The authors gratefully acknowledge the support of the PSC-NICHD/PARC/Boettner Center, USDA, Economic Research Service (Grant \# 58-4000-7-0058, and the Hewlett Foundation on this work. The sponsors/funders have had no role in the design and conduct of the study; collection, management, analysis, and interpretation of the data; and preparation, review, or approval of the manuscript. Dr. Volpp had full access to all of the data in the study and takes responsibility for the integrity of the data and the accuracy of the data analysis.

\section{References}

1. Flegal KM, Carroll MD, Ogden CL, Johnson CL. Prevalence and trends in obesity among US adults, 1999-2000. Jama. Oct 9; 2002 288(14):1723-1727. [PubMed: 12365955]

2. Ogden CL, Carroll MD, Curtin LR, McDowell MA, Tabak CJ, Flegal KM. Prevalence of overweight and obesity in the United States, 1999-2004. Jama. Apr 5; 2006 295(13):1549-1555. [PubMed: 16595758]

3. Flegal KM, Graubard BI, Williamson DF, Gail MH. Excess deaths associated with underweight, overweight, and obesity. JAMA. Apr 20; 2005 293(15):1861-1867. [PubMed: 15840860]

4. Laibson DI. Golden eggs and hyperbolic discounting. Quarterly Journal of Economics. 1997; 62:443-477.

5. O’Donoghue T, Rabin M. Doing it now or later. American Economic Review. 1999; 89(1):103-124. 
6. Loewenstein G, Brennan T, Volpp KG. Asymmetric paternalism to improve health behaviors. Jama. Nov 28; 2007 298(20):2415-2417. [PubMed: 18042920]

7. National Institutes of Health. Clinical Guidelines on the Identification, Evaluation, and Treatment of Overweight and Obesity in Adults--The Evidence Report. Obes Res. Sep; 1998 6(Suppl 2):51S209S. [PubMed: 9813653]

8. Knowler WC, Barrett-Connor E, Fowler SE, et al. Reduction in the incidence of type 2 diabetes with lifestyle intervention or metformin. N Engl J Med. Feb 7; 2002 346(6):393-403. [PubMed: 11832527]

9. Yancy, WS., Jr; Boan, J. Adherence to Diet Recommendations. In: Bosworth, HB.; Oddone, EZ.; Weinberger, M., editors. Patient Treatment Adherence: Concepts, Interventions, and Measurement. Mahwah, NJ: Lawrence Erlbaum Associates, Inc; 2005.

10. Finkelstein EA, Linnan LA, Tate DF, Birken BE. A pilot study testing the effect of different levels of financial incentives on weight loss among overweight employees. J Occup Environ Med. Sep; 2007 49(9):981-989. [PubMed: 17848854]

11. Jeffery RW, Gerber WM, Rosenthal BS, Lindquist RA. Monetary contracts in weight control: effectiveness of group and individual contracts of varying size. J Consult Clin Psychol. Apr; 1983 51(2):242-248. [PubMed: 6841768]

12. Jeffery RW, Thompson PD, Wing RR. Effects on weight reduction of strong monetary contracts for calorie restriction or weight loss. Behav Res Ther. 1978; 16(5):363-369. [PubMed: 743075]

13. Higgins ST, Wong CJ, Badger GJ, Ogden DE, Dantona RL. Contingent reinforcement increases cocaine abstinence during outpatient treatment and 1 year of follow-up. J Consult Clin Psychol. Feb; 2000 68(1):64-72. [PubMed: 10710841]

14. Sindelar J. Paying for Performance: the power of incentives over habits. Health Economics. 2008; 17(4):449-451. [PubMed: 18348117]

15. Higgins, ST. Applying Behavioral Economics to the Challenge of Reducing Cocaine Abuse. In: Chaloupka, FJ.; Grossman, M.; Bickel, WK.; Saffer, H., editors. The Economic Analysis of Substance Use and Abuse. Cambridge, MA: NBER; 1999. p. 157-174.

16. Giuffrida A, Torgenson DJ. Should We Pay the Patient? Review of Financial Incentives to Enhance Patient Compliance. BMJ. 1997; 315(7110):703-707. [PubMed: 9314754]

17. Schroeder SA, Shattuck Lecture. We can do better--improving the health of the American people. N Engl J Med. Sep 20; 2007 357(12):1221-1228. [PubMed: 17881753]

18. Ainslie G. Specious reward: a behavioral theory of impulsiveness and impulse control. Psychological Bulletin. 1975; 82:463-496. [PubMed: 1099599]

19. Thaler RH. Some empirical evidence on time inconsistency. Review of Economic Studies. 1981; 23:165-180.

20. Loewenstein G, Prelec D. Anomalies in intertemporal choice: Evidence and an interpretation. Quarterly Journal of Economics. 1992; 107:573-597.

21. Kirby K. Bidding on the future: evidence against normative discounting of delayed rewards. Journal of Experimental Psychology: General. 1997; 126:54-70.

22. Camerer C, Ho T-H. Experience-Weighted Attraction Learning in Normal Form Games. Econometrica. 1999; 67:837-874.

23. Loewenstein G, Weber EU, Hsee CK, Welch N. Risk as feelings. Psychological Bulletin. 2001; 127(2):267-286. [PubMed: 11316014]

24. Connolly T, Butler DU. Regret in Economic and Psychological Theories of Choice. Journal of Behavioral Decision Making. 2006; 19(2):148-158.

25. Chapman GB, Coups EJ. Emotions and Preventive Health Behavior: Worry, Regret, and Influenza Vaccination. Health Psychol. 2006; 25(1):82-90. [PubMed: 16448301]

26. Bandura, A. Principles of Behavior Modification. New York: Holt: Rinehart and Winston, Inc.; 1969.

27. Thaler RH, Tversky A, Kahneman AS DR. The Effect of Myopia and Loss Aversion on Risk Taking: An Experimental Test. Quarterly Journal of Economics. 1997; 112:647-661.

28. Rizzo JA, Zeckhauser RJ. Reference incomes, loss aversion, and physician behavior. The Review of Economics and Statistics. 2003; 85(4):909-922. 
29. Camerer C. Three Cheers--Psychological, Theoretical, Empirical--for Loss Aversion. Journal of Marketing Research. 2005; 42(2):129-133.

30. Read D, Loewenstein G, Rabin M. Choice Bracketing. Journal of Risk and Uncertainty. 1999; 19:171-197.

31. McTigue KM, Harris R, Hemphill B, et al. Screening and interventions for obesity in adults: summary of the evidence for the U.S. Preventive Services Task Force. Ann Intern Med. Dec 2; 2003 139(11):933-949. [PubMed: 14644897]

32. Strategic plan for NIH Obesity Research. A report of the NIH Obesity Research Task Force. Aug. 2006 http://www.obesityresearch.nih.gov

33. Obesity. Preventing and managing the global epidemic. Geneva, Switzerland: World Health Organization; 1998.

34. Mokdad AH, Bowman BA, Ford ES, Vinicor F, Marks JS, Koplan JP. The continuing epidemics of obesity and diabetes in the United States. Jama. Sep 12; 2001 286(10):1195-1200. [PubMed: 11559264]

35. Red Book 2002 Drug Topics: The Pharmacist's trusted companion for more than a century. Montvale, NJ: Medical Economics Company; 2002.

36. Encinosa WE, Bernard DM, Chen CC, Steiner CA. Healthcare utilization and outcomes after bariatric surgery. Med Care. Aug; 2006 44(8):706-712. [PubMed: 16862031] 


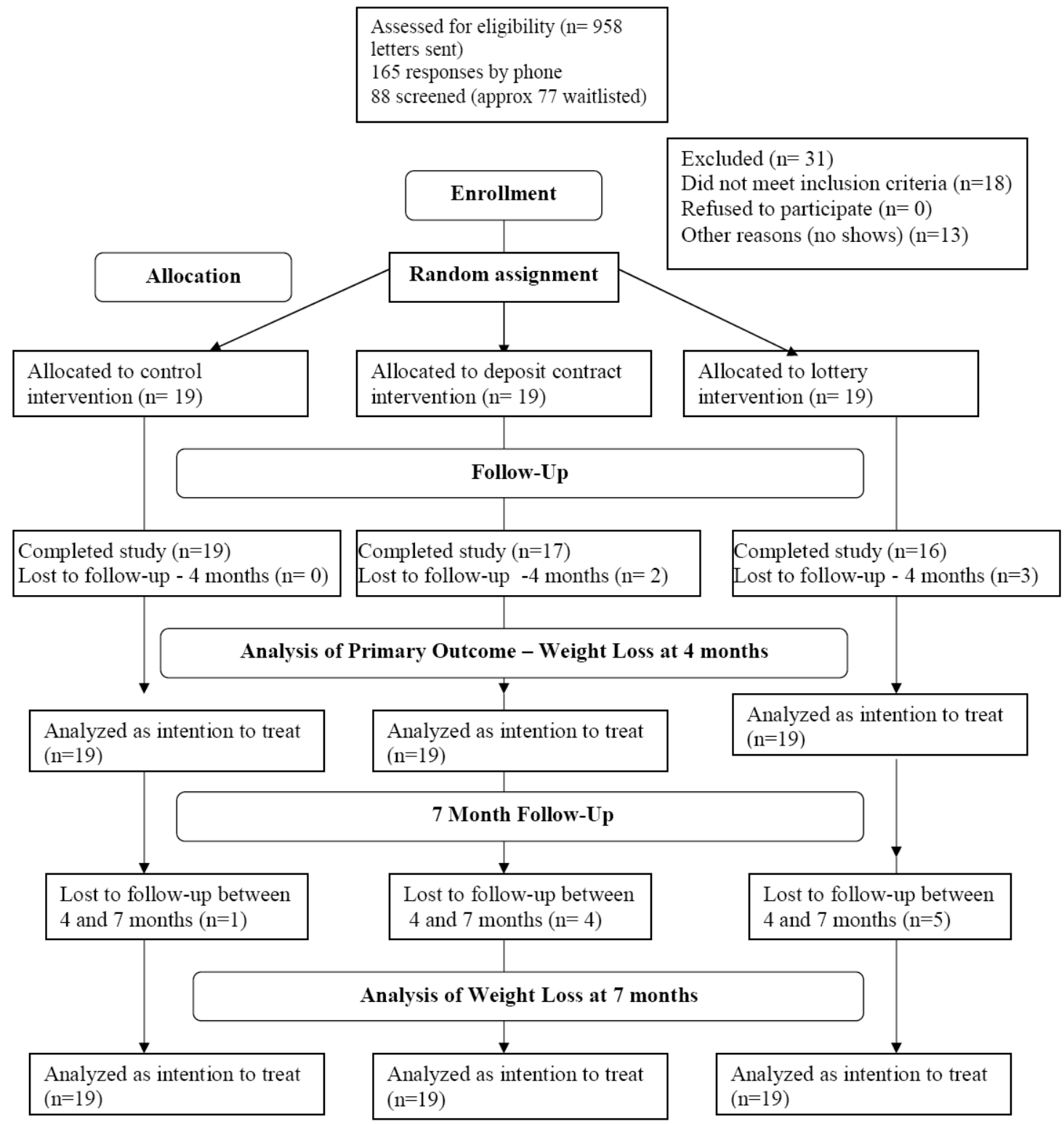

Figure 1. Flow of study 


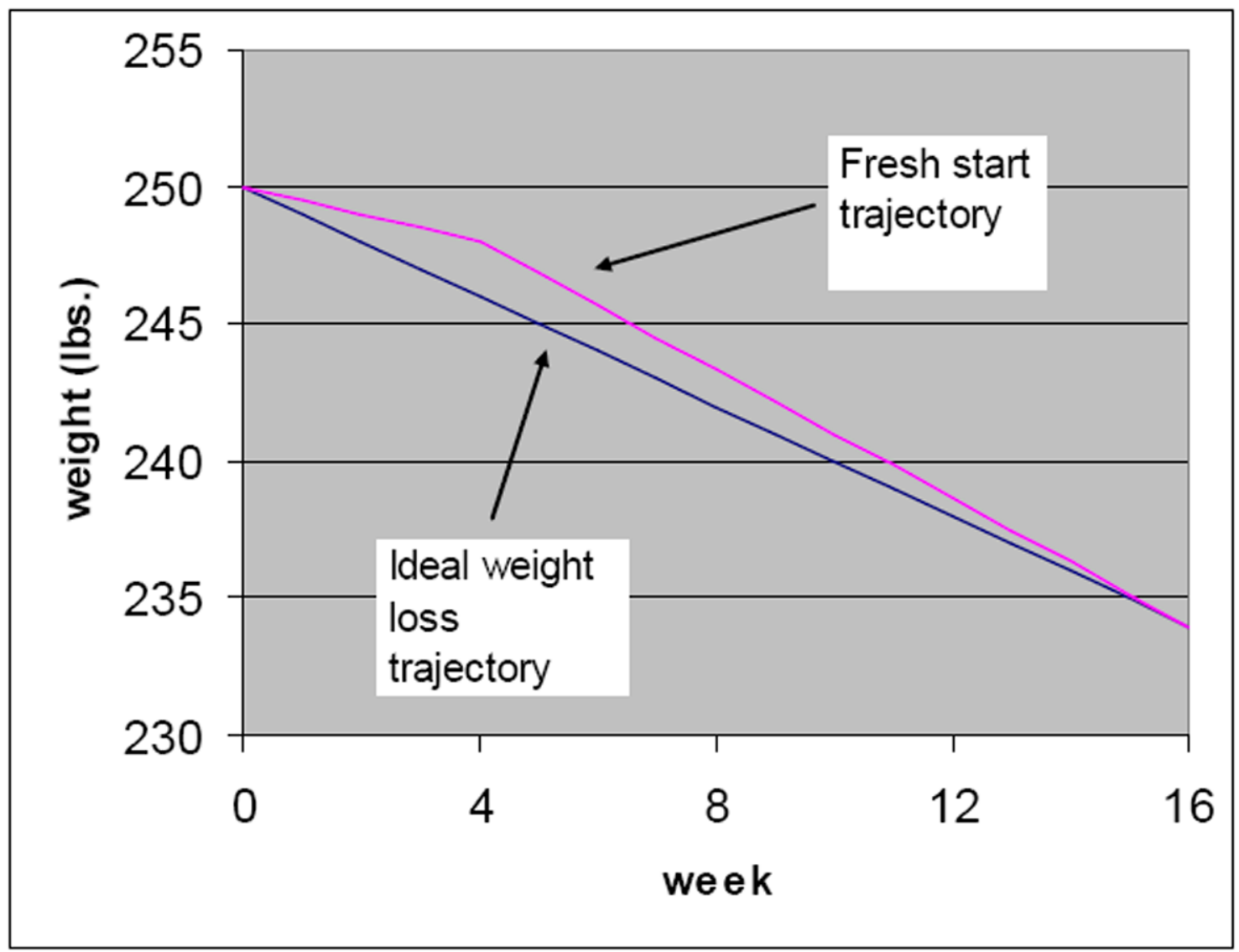

Figure 2. Diagram of Sample Participant Weight Loss Goals

This figure demonstrates the sample weight loss goal for a subject who at study initiation weighed 250 pounds. Each subject was given the goal weight loss of 1 pound per week for 16 weeks. The "Fresh Start" trajectory illustrates an approach that was taken to minimize drop-out in subjects who were unable to initially stay on target. For example, if this subject lost 1 pound after 4 weeks, the slope of their weight loss goal targets was simply adjusted so that while they still had the same goal after 16 weeks, he/she would not have to suddenly lose 3 pounds to become eligible for continued incentives. 


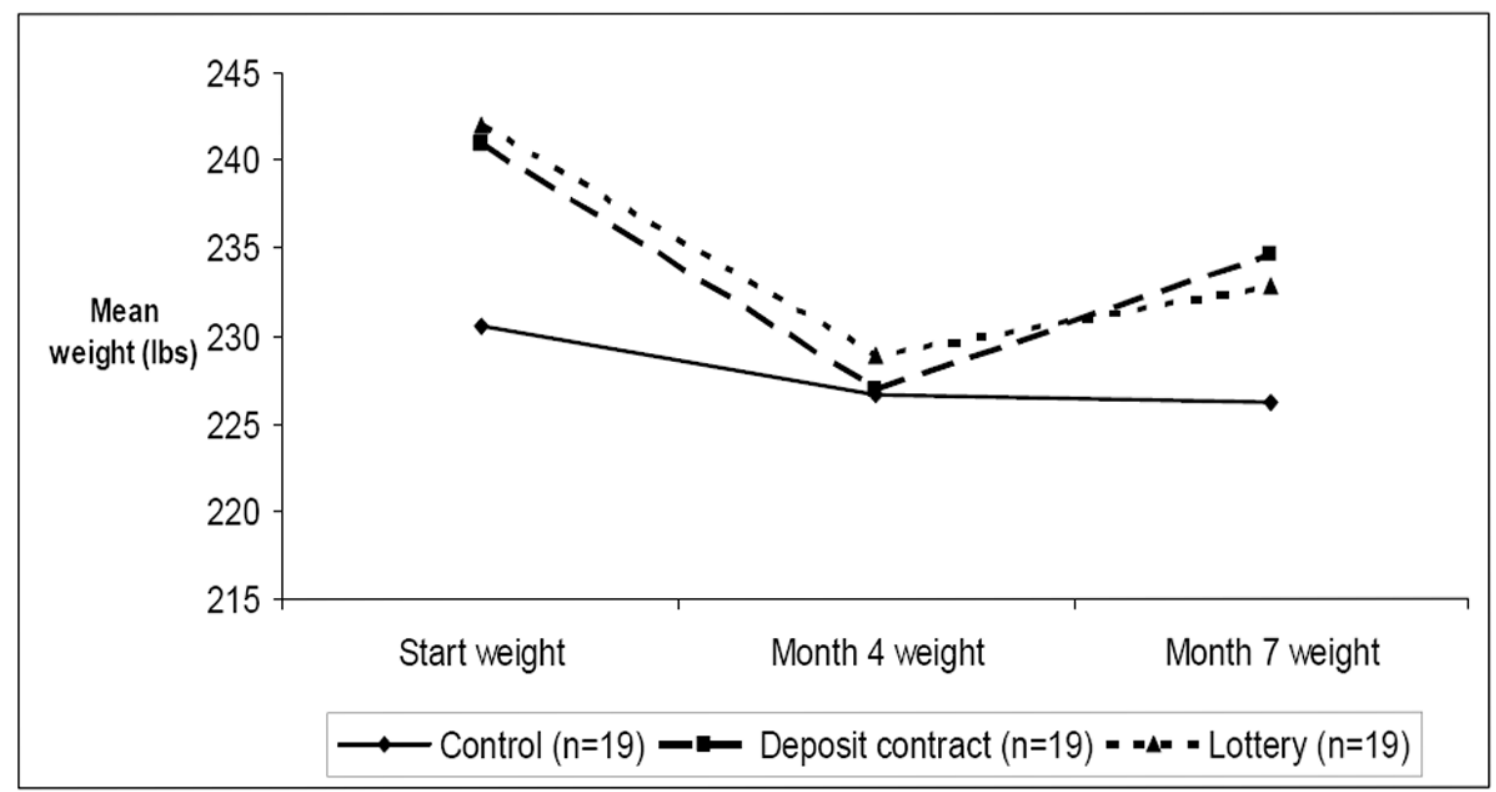

Figure 3. Weight loss by arm in control and incentive groups from enrollment to the end of 7 months

Study participants in each of the incentive arms regained weight between 4 and 7 months following enrollment, though participants in the incentive arms experienced net weight loss between enrollment and 7 months and participants in the control arm did not. Weight loss was significantly greater in the incentive conditions relative to control at 4 months (L: $\mathrm{p}=$. 014; DC: $\mathrm{p}=.003)$, but not at 7 months (L: $\mathrm{p}=.23$; DC: $\mathrm{p}=.61)$. 


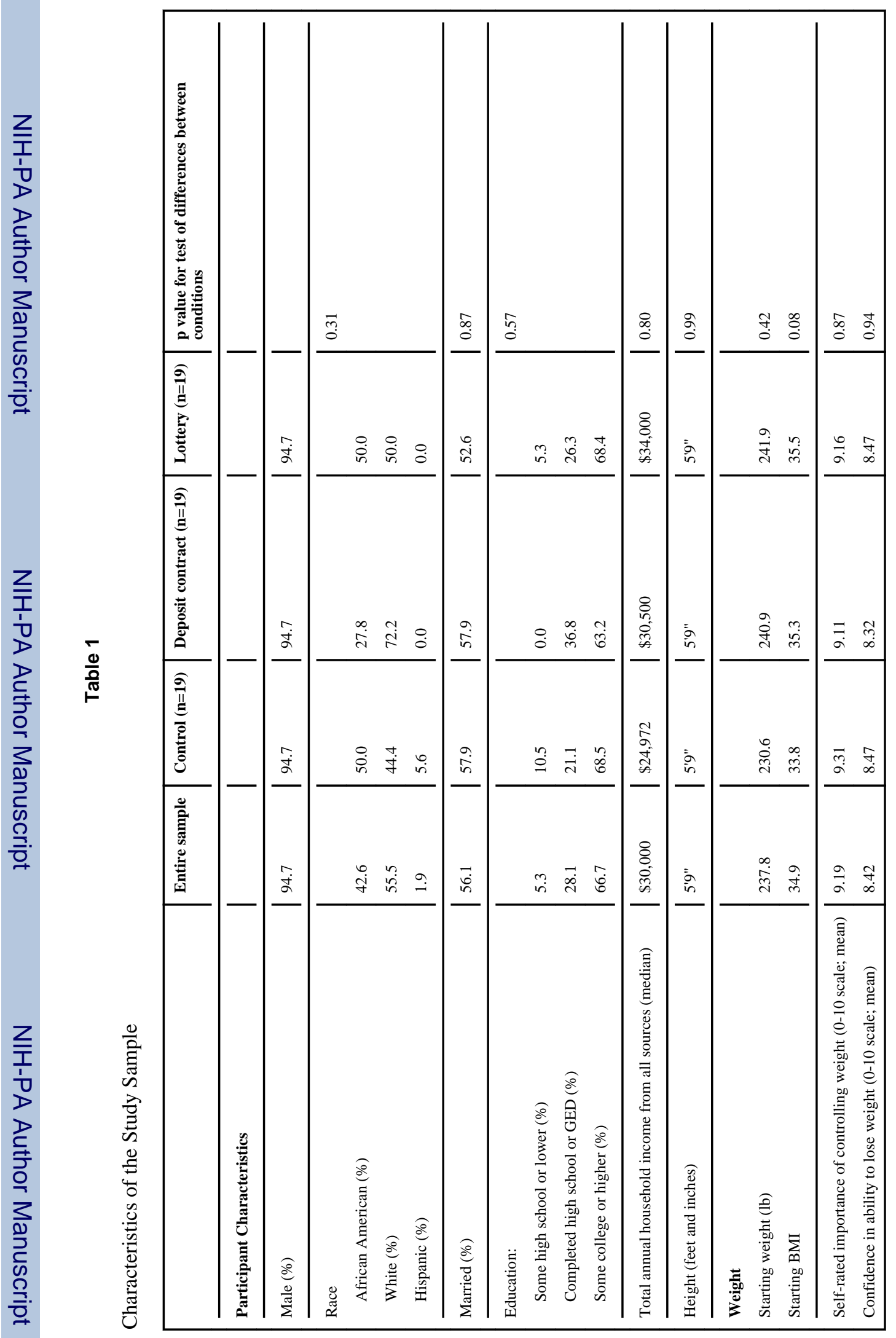

JAMA. Author manuscript; available in PMC 2013 February 27. 
Table 2

Weight loss by arm in control and incentive groups after 16 weeks

\begin{tabular}{|l|l|l|l|}
\hline Measure & Control & Deposit contract & Lottery \\
\hline Mean total weight loss (lbs) (95\% confidence interval) & $3.9(0.20$ gain, 13.2) & $14.0^{*}(9.4,18.6)$ & $13.1^{*}(7.4,18.8)$ \\
\hline Percent who met 16-pound weight loss goal & $10.5(1.3-33.1)$ & $47.4^{*}(24.4-71.1)$ & $52.6^{*}(28.9-75.5)$ \\
Percent who lost more than 20 pounds & $5.3(0.13-26.0)$ & $36.8^{*}(16.3-61.6)$ & $26.3^{*}(9.2-51.2)$ \\
\hline
\end{tabular}

Difference between incentive and control conditions significant at $\mathrm{p} \leq .05$ 